\title{
Inhaled magnesium fluoride reverse bronchospasma
}

\author{
Fedoua GANDia ${ }^{1}$, Sonia RouatBi ${ }^{1}$, Imed LATIRI $^{1}$, \\ Hervé GUÉNARD ${ }^{2}$ and Zouhair TABKA ${ }^{1}$ \\ ${ }^{1}$ Laboratory of Physiology and Functional Explorations, CHU Farhat Hached, France \\ ${ }^{2}$ Laboratory of Physiology, Faculty of Victor Panchon, University of Bordeaux 2, France
}

Received February 16, 2010; Accepted April 17, 2010

\begin{abstract}
Asthma is a global health problem. Asthma attacks are becoming more severe and more resistant to usual treatment by $\beta_{2}$ agonists nebulisation. The search for a new product that could reduce the morbidity of asthmatic disease seems necessary. The objective of this study was to compare the effectiveness of inhaled magnesium fluoride $\left(\mathrm{MgF}_{2}\right)$ with that of magnesium sulphate $\left(\mathrm{MgSO}_{4}\right) 15 \%$ alone and sodium fluoride $(\mathrm{NaF}) 0.5 \mathrm{M}$ alone in rats precontracted by methacholine $(\mathrm{MeCh})$. Fifty six adult male Wistar rats of medium weight $259 \pm$ $15 \mathrm{~g}$ were divided randomly into five groups. They inhaled respectively: $\mathrm{MeCh}, \mathrm{MgF}_{2}+\mathrm{NaCl}$ $0.9 \%, \mathrm{MgF}_{2}+$ acetic acid, $\mathrm{MgSO}_{4} 15 \%$ single and $\mathrm{NaF}(0.5 \mathrm{M})$ single. Airway resistances were measured after each dose of $\mathrm{MeCh}$ by pneumomultitest equipment. Results indicated that (1) $\mathrm{MgF}_{2}+\mathrm{NaCl} 0.9 \%, \mathrm{MgF}_{2}+$ acetic acid and $\mathrm{MgSO}_{4}$ reversed significantly the methacholine-induced bronchial constriction in rats and had a bronchodilating effect at the moment of its administration (2) $\mathrm{MgF}_{2}+$ acetic acid led to a greater decrease $(P<0.05)$ of bronchial resistances when compared to that obtained from $\mathrm{MgF}_{2}+\mathrm{NaCl} 0.9 \%, \mathrm{NaF}$ exclusively and $\mathrm{MgSO}_{4}$ alone (3) inhaled $\mathrm{NaF}$ alone led to a significant bronchorelaxing effect $(P<0.05)$ that starts at the sixth dose of $\mathrm{MeCh}(17 \mathrm{mg} / \mathrm{L})$. As a matter of fact, $\mathrm{MgF}_{2}$ dissolved in acetic acid and delivered in aerosol form reduces significantly bronchial spasm. In conclusion, $\mathrm{MgF}_{2}$ can be used as a bronchodilator for diseases with bronchospasma such as asthma and chronic obstructive pulmonary disease (COPD).
\end{abstract}

Key words: magnesium fluoride, sodium fluoride, sulphate magnesium, airway resistance, rat

\section{Introduction}

Despite the progress made on the management of asthma, the prevalence, morbidity and mortality of this disease seems constantly increasing. During an asthma attack, the smooth muscle in the airway contracts more than it should, which causes an increase of bronchial resistances values (R) and so dyspnea (Stephens, 2002).

$\mathrm{NaF}$ is an inhibitor of enolase, an enzyme of the glycolysis pathway leading to phosphoenolpyruvate. Oral NaF was initially examined in the treatment of osteoporosis by

Correspondence to: Dr. Fedoua Gandia, Laboratoire de Physiologie et des Explorations Fonctionnelles, CHU

Farhat Hached, 4000, Sousse, Tunisia

Phone: +216-73222600 Fax: +216-73224899 e-mail: gandiafedoua1@yahoo.fr 
Charles et al. (1989). Cushing et al. (1990) found that NaF relaxed arteries by releasing an endothelium derived relaxing factor and one or more prostanoids. Whereas, inhaled effect of $\mathrm{NaF}$ was poorly documented. It had been shown that inhaled $\mathrm{NaF}$, induce bronchial relaxation on pre contracted bovine bronchi in vitro and in rats in vivo (Zhao and Guénard, 1997; Zhao et al., 2002).

$\mathrm{MgSO}_{4}$ is an agent that has been given as an additive treatment of patients with acute asthma and has been shown to be effective in patients with severe acute asthma when delivered parentrally (Rowe et al., 2000). Magnesium may be effective in acute asthma through one or more of a variety of mechanisms. Magnesium relaxes smooth muscle and inhibits the smooth muscle contraction (Gourgoulianis et al., 2001). This theory has been proposed as an explanation for the beneficial effects of $\mathrm{MgSO}_{4}$ in patients with acute asthma. However, this explanation may be too simplistic. Magnesium is also involved with cellular homeostasis through its role as an enzymatic cofactor, as well as being involved in acetylcholine and histamine release, from cholinergic nerve terminals and mast cells, respectively. Investigators have proposed that the effect of $\mathrm{MgSO}_{4}$ is related to its ability to block the calcium ion influx to smooth muscles of the respiratory system (Gourgoulianis et al., 2001). Finally, the role of $\mathrm{MgSO}_{4}$ as an anti-inflammatory has been identified in adults with asthma (Carins and Kraft, 2001).

The use of $\mathrm{MgSO}_{4}$ is one of numerous options available during exacerbations of asthma (Noppen, 1990). While the efficiency of intravenous $\mathrm{MgSO}_{4}$ in these cases has been demonstrated, little is known about inhaled $\mathrm{MgSO}_{4}$. The potential clinical benefit of inhaled $\mathrm{MgSO}_{4}$ has been studied, and research publications have produced conflicting results (Hill et al., 1997; Rolla et al., 1988). Consequently, this agent is not currently recommended as part of the current guidelines and has not been used widely in most acute cases. The few times that inhaled magnesium has been mentioned, it has been as a minor effect (Harari et al., 1998).

Fluoride and magnesium ions $\left(\mathrm{F}^{-}\right.$and $\mathrm{Mg}^{2+}$ ) associated in $\mathrm{MgF}_{2}$ could have a major bronchorelaxing effect. In theory, these two ions act additively and synergicely, accordingly $\mathrm{MgF}_{2}$ could be an efficient pharmacological compound against bronchospasm. The bronchorelaxing effect of this product $\mathrm{MgF}_{2}$ has never been tested.

In Tunisia, where this research was conducted, $\mathrm{MgF}_{2}$ is an abundant mineral and inexpensive element that could be useful for the treatment of asthmatics.

The purpose of this study was to compare bronchodilating effects obtained by inhaled compounds: $\mathrm{NaF}, \mathrm{MgSO}_{4}$ and $\mathrm{MgF}_{2}$.

\section{Subjects and Methods}

\section{Subjects}

Fifty six adult male Wistar rats (weight, $259 \pm 15 \mathrm{~g}$; mean $\pm \mathrm{SE}$ ). Rats were divided randomly into five groups treated with the following drugs respectively: methacholine $(\mathrm{MeCh})(\mathrm{n}=12), \mathrm{MgF}_{2}$ $+\mathrm{NaCl} 0.9 \%(\mathrm{n}=13), \mathrm{MgF}_{2}+$ acetic acid ( $\left.\mathrm{n}=12\right), \mathrm{NaF} 0.5 \mathrm{M}(\mathrm{n}=8)$ and $\mathrm{MgSO}_{4}(\mathrm{n}=11)$.

Rats were anesthetized intraperitoneally with ketamine $(150 \mathrm{mg} / \mathrm{kg})$. After dissecting the neck, a tracheal cannula was inserted into a mid-line incision of the trachea. A catheter was inserted into oesophagus and connected to a pressure transducer to measure the intra-oesophageal pressure. A small pneumotachograph (PTG, 8431B, Hans Rudolph, Kausas, USA) was connected 
to tracheal cannula. The period of measurement of the flow rate with the PTG was set at $10 \mathrm{sec}$ to avoid change in ventilation due to the PTG dead volume. The PTG was connected to a differential pressure transducer. Both pressure and flow transducers were assembled together with connecting valves to ease the calibration. Calibration in volume was done daily with a $10 \mathrm{ml}$ syringe. Total lung resistance (R) was calculated by using a first order mechanical model of the lung. Aerosolizations were made through a DeVilbiss nebulizer (Ref. 123016 Marquette Medical products, Englewood Co., USA) connected to a compressor (flow rate $100 \mathrm{ml} / \mathrm{s}$ ). Aerosols were delivered at a flow rate of $0.1 \mathrm{ml} / \mathrm{s}$ in a rigid plastic chamber placed over the rat body (Zhao et al., 2002).

Bronchoconstriction was induced by gradually increasing concentrations of MeCh: $0.5 \mathrm{mg} / \mathrm{L}, 1$ $\mathrm{mg} / \mathrm{L}, 2.12 \mathrm{mg} / \mathrm{L}, 4.25 \mathrm{mg} / \mathrm{L}, 8.5 \mathrm{mg} / \mathrm{L}, 17 \mathrm{mg} / \mathrm{L}, 34 \mathrm{mg} / \mathrm{L}$ and $68 \mathrm{mg} / \mathrm{L}$. MeCh solutions were aerosolized within the chamber for $1 \mathrm{~min}$ with $3 \mathrm{~min}$ intervals between doses.

$\left(\mathrm{MgF}_{2}+\mathrm{NaCl} 0.9 \%\right),\left(\mathrm{MgF}_{2}+\right.$ acetic acid), $\mathrm{NaF}$ and $\mathrm{MgSO}_{4}$ inhaled aerosols were delivered for one minute after each dose of $\mathrm{MeCh}$ from the fourth dose of $\mathrm{MeCh}$. The total lung resistances (R) were measured before the challenge, after an aerosol of isotonic saline and 2 minutes after each dose of $\mathrm{MeCh}$.

\section{Protocols}

Animal experiment protocols used in the present study were approved by the Animal Ethics Committee of the Faculty of Medicine of Sousse, Tunisia, where the experiments were carried out. Five protocols were made:

Protocol 1: MeCh was administrated to $(\mathrm{MeCh})$ group, $(\mathrm{n}=12)$ at increasing doses $(0.5,2.12$, 4.25, 8.5, 17, 34, $68 \mathrm{mg} / \mathrm{L})$. The total lung resistance (R) was measured after each dose of MeCh.

Protocol 2: The rats of the $\left(\mathrm{MgF}_{2}+\mathrm{NaCl} 0.9 \%\right)$ group, $(\mathrm{n}=13)$ were firstly challenged by increasing doses of $\mathrm{MeCh} . \mathrm{MgF}_{2}$ dissolved in $\mathrm{NaCl} 0.9 \%(\mathrm{Mg}=0.04 \mathrm{mM}, \mathrm{F}=0.014 \mathrm{mM})$ in aerosol form was delivered at the fourth dose of $\mathrm{MeCh}(4.25 \mathrm{mg} / \mathrm{L})$.

Protocol 3: The rats of the $\left(\mathrm{MgF}_{2}\right.$ dissolved in acetic acid) group, $(\mathrm{n}=12)$ were firstly challenged by increasing doses of $\mathrm{MeCh}$. Then, $\mathrm{MgF}_{2}$ dissolved in acetic acid $(\mathrm{Mg}=0.08 \mathrm{mM}$, $\mathrm{F}=0.084 \mathrm{mM})$ was delivered in aerosol form at the fourth dose of $\mathrm{MeCh}(4.25 \mathrm{mg} / \mathrm{L})$.

Protocol 4: The $(\mathrm{NaF})$ group, $(\mathrm{n}=8)$ was firstly challenged by increasing doses of $\mathrm{MeCh} . \mathrm{NaF}$ $(0.5 \mathrm{M})$ exclusively, in aerosol form, was delivered at the fourth dose of $\mathrm{MeCh}(4.25 \mathrm{mg} / \mathrm{L})$.

Protocol 5: The $\left(\mathrm{MgSO}_{4}\right)$ group, $(\mathrm{n}=11)$ was firstly challenged by increasing doses of $\mathrm{MeCh}$, $\mathrm{MgSO}_{4} 15 \%$ single, in aerosol form, was delivered at the fourth dose of $\mathrm{MeCh}(4.25 \mathrm{mg} / \mathrm{L})$.

\section{Chemicals used}

$\mathrm{MgSO}_{4}, \mathrm{NaF}$, acetic acid and ketamine were purchased from Sigma (St. Louis, MI, USA) and methacholine from Allerbio (La varenne, France). NaF was dissolved in distilled water devoid of traces of aluminium. $\mathrm{MgF}_{2}$ was dissolved in acetic acid to improve the solubility. Magnesium fluoride, random crystals, 99.99+\%, optical grade: purchased from (Sigma, Aldrich).

\section{Data analysis}

All data were reported as a mean \pm SEM. A $P$ value $<0.05$ was considered significant. Mean 
values of $\mathrm{R}$ between control and other groups were compared using the Mann-Withney $\mathrm{U}$ test. Comparison of rat's resistances (R) values among the same group of rats at different concentrations of $\mathrm{MeCh}$ was made using the paired Student's $t$-test. Changes in $\mathrm{R}$ during the methacholine challenge in different groups were analysed with a two-way ANOVA.

\section{Results}

\section{Effects of methacholine inhalation on $(R)$ values}

After the inhalation of methacholine, $(\mathrm{R})$ values increased proportionally with increases in the methacholine concentration. Figure 1 shows the $(\mathrm{R})$ values at different concentrations of methacholine. A significant increase in bronchial resistance $(P<0.05)$ at the fourth dose of methacholine (4.25 mg/L) was observed (Fig. 1).

\section{Effects of $M g F_{2}$ inhalation on $(R)$ values}

Inhaled $\left(\mathrm{MgF}_{2}+\mathrm{NaCl} 0.9 \%\right)$ and $\left(\mathrm{MgF}_{2}+\right.$ acetic acid $)$ reversed significantly the methacholine-induced bronchial constriction in rats at the moment of its administration (fourth dose of MeCh, $4.25 \mathrm{mg} / \mathrm{L}$ ) (Fig. 1).

The dissolution of $\mathrm{MgF}_{2}$ in acetic acid led to an increase in the total molar concentrations of magnesium and fluoride in the solution compared to its dissolution in $\mathrm{NaCl} 0.9 \%: \mathrm{MgF}_{2}$ dissolved in acetic acid $\left(\mathrm{Mg}=0.08 \mathrm{mM}, \mathrm{F}=0.084 \mathrm{mM}\right.$, solubility $\left.=0.126 .10^{-3}\right) \mathrm{MgF}_{2}+\mathrm{NaCl} 0.9 \%(\mathrm{Mg}=0.04$ $\mathrm{mM}, \mathrm{F}=0.014 \mathrm{mM}$, solubility $\left.=0.521 .10^{-3}\right) . \quad \mathrm{MgF}_{2}$ pure crystals $99.99+\%$ were used to avoid any contaminations with other elements which could fault the results like calcium that plays an important role in the contraction of smooth muscle.

Inhaled $\left(\mathrm{MgF}_{2}+\right.$ acetic acid) led to a greater decrease $(P<0.05)$ of $(\mathrm{R})$ values, when compared to those obtained with $\mathrm{MgF}_{2}+\mathrm{NaCl} 0.9 \%$ (Fig. 1).

The comparison between $\left(\mathrm{MgF}_{2}+\mathrm{NaCl} 0.9 \%\right)$ and $\left(\mathrm{MgF}_{2}+\right.$ acetic acid) groups using MannWhitney U-test revealed significant difference $(P<0.05)$ in the three highest concentrations of $\operatorname{MeCh}(17,34,68 \mathrm{mg} / \mathrm{L})$.

Effects of $N a F(0.5 M)$ inhalation on ( $R$ ) values

Inhaled $\mathrm{NaF}$, administrated at the fourth dose of methacholine, led to a meaningful bronchorelaxing effect $(P<0.05)$ that starts at the sixth dose of $\mathrm{MeCh}(17 \mathrm{mg} / \mathrm{L})(\mathrm{Fig} .2)$.

Effects of $\mathrm{MgSO}_{4}(15 \%)$ inhalation on $(R)$ values

Inhaled $\mathrm{MgSO}_{4} 15 \%$ reversed significantly $(P<0.05)$ the methacholine-induced bronchial constriction in rats at the moment of its administration (fourth dose of $\mathrm{MeCh}, 4.25 \mathrm{mg} / \mathrm{L}$ ) (Fig. 2).

\section{Discussion}

The main findings of this study were: (1) $\mathrm{MgF}_{2}+\mathrm{NaCl} 0.9 \%, \mathrm{MgF}_{2}+$ acetic acid and $\mathrm{MgSO}_{4}$ reversed significantly the methacholine-induced bronchial constriction in rats and had a bronchodilating effect at the moment of its administration (2) $\mathrm{MgF}_{2}+$ acetic acid led to a greater 


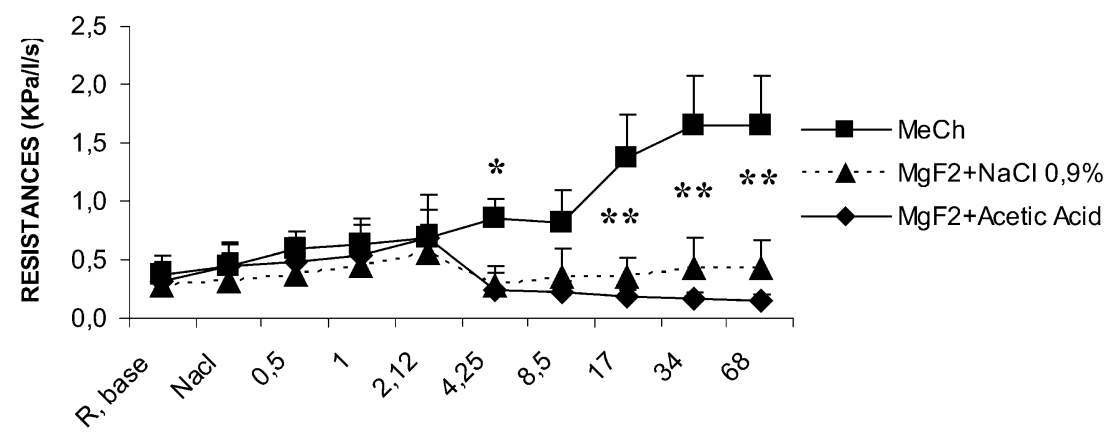

$\operatorname{MeCh}(\mathrm{mg} / \mathrm{L})$

Fig. 1. Effects of inhaled $\mathrm{MgF}_{2}+\mathrm{NaCl} 0.9 \%(\mathrm{n}=13)$ and $\mathrm{MgF}_{2}+$ acetic acid $(\mathrm{n}=12)$, on airway resistances $(\mathrm{R})$ of rat challenged by methacholine $(\mathrm{MeCh})(\mathrm{n}=12) . \quad *, P<0.05$, significant increase in bronchial resistance that starts at the fourth dose of $\mathrm{MeCh}(4.25 \mathrm{mg} / \mathrm{L})$. **, $P<0.05$, Mann-Whitney $\mathrm{U}$ test. The comparison between $\left(\mathrm{MgF}_{2}+\mathrm{NaCl} 0.9 \%\right)$ and $\left(\mathrm{MgF}_{2}+\right.$ acetic acid) groups using Mann-Whitney $\mathrm{U}$ test revealed significant differences in bronchial resistance $(P<0.05)$ that starts at the sixth dose of $\mathrm{MeCh}(17 \mathrm{mg} / \mathrm{L})$.

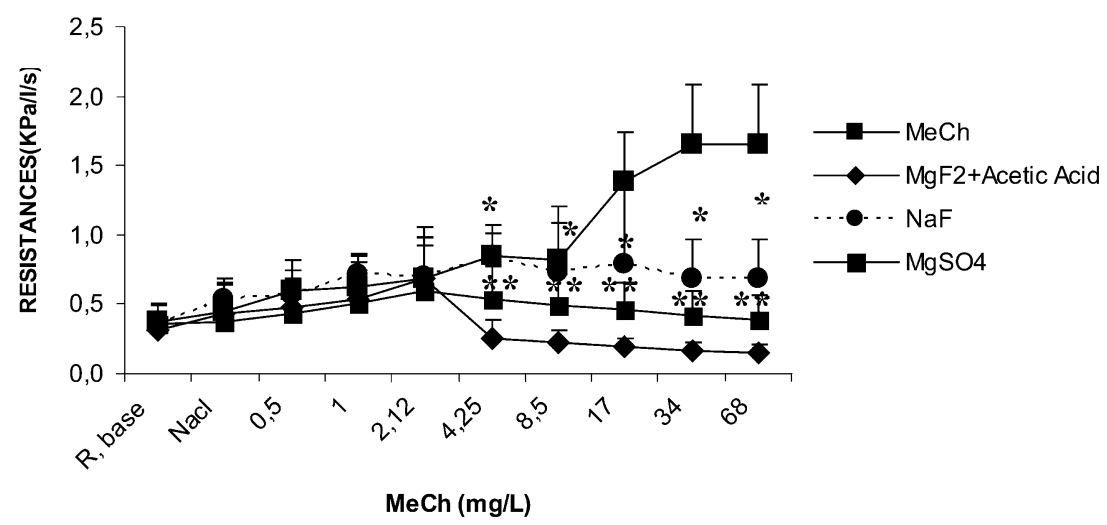

Fig. 2. Effects of inhaled $\mathrm{MgSO}_{4}(\mathrm{n}=11), \mathrm{NaF} 0.5 \mathrm{M}(\mathrm{n}=8)$ and $\mathrm{MgF}_{2}+$ acetic acid $(\mathrm{n}=12)$, on airway resistances $(\mathrm{R})$ of rat challenged by methacholine $(\mathrm{MeCh})(\mathrm{n}=12)$. *, $P<0.05$, Mann-Whitney $\mathrm{U}$ test. The comparison between $\left(\mathrm{MgF}_{2}+\right.$ acetic acid) and $\mathrm{NaF}$ groups using Mann-Whitney $\mathrm{U}$ test revealed significant differences in bronchial resistance $(P<0.05)$ that starts at the fourth dose of $\mathrm{MeCh}(4.25 \mathrm{mg} / \mathrm{L}) . * *, P<0.05$, MannWhitney $\mathrm{U}$ test. The comparison between $\left(\mathrm{MgF}_{2}+\right.$ acetic acid) and $\mathrm{MgSO}_{4}$ groups using Mann-Whitney $\mathrm{U}$ test revealed significant differences in bronchial resistance $(P<0.05)$ that starts at the fourth dose of $\mathrm{MeCh}(4.25 \mathrm{mg} / \mathrm{L})$.

decrease $(P<0.05)$ of bronchial resistance when compared to those obtained with $\mathrm{MgF}_{2}+\mathrm{NaCl}$ $0.9 \%, \mathrm{NaF}$ alone and $\mathrm{MgSO}_{4}$ alone (3) inhaled $\mathrm{NaF}$ alone led to a meaningful bronchorelaxing effect $(P<0.05)$ that starts at the sixth dose of $\mathrm{MeCh}(17 \mathrm{mg} / \mathrm{L})$.

The anaesthesia of rat by Ketamin was based on its easy administration, low toxicity, good conservation of ventilation and its very high lethal doses on animals (Riou and Ducart, 1994; Dureuil, 1996). Methacholine was used to challenge the rat before any administration. In fact, methacholine was reported as a synthetic muscarinic agonist more stable than acetylcholine 
(destructed by the cholinesterase) and better tolerated than histamine or carbachol. In addition, $\mathrm{MeCh}$ rarely induced a cough (Wanger, 1996; Sterck et al., 2001).

$\mathrm{NaF}$ is less potent than aluminium fluoride $\left(\mathrm{AlF}^{-}{ }_{4}\right)$ in the activation of $\mathrm{G}$ proteins. $\mathrm{AlF}^{-}{ }_{4}$ mimics the action of GTP at micromolar concentrations by inducing dissociation of the $\alpha$ subunit of G protein followed by the calcium channel modulation (Stadel and Crooke, 1988). A possible contamination of $\mathrm{Al}$ from the glass ware might have affected the results obtained with $\mathrm{NaF}$. When $\mathrm{F}^{-}$is diluted in the solution, some $\mathrm{Al}$ is extracted from the surface of the glass to form $\mathrm{AlF}_{4}^{-}$. This phenomenon was excluded in the present study because all fluoride solutions were prepared and stored in polyethylene bottles in order to prevent attack on glass surfaces. The choice of NaF dose $(0.5 \mathrm{M})$ was based on findings of Zhao et al., 2002 which demonstrated that at this concentration we obtained a decrease of airway resistances (Zhao et al., 2002). All compounds: $\left(\mathrm{MgF}_{2}+\mathrm{NaCl} 0.9 \%\right)$, $\left(\mathrm{MgF}_{2}+\right.$ acetic acid), $\mathrm{NaF}$ and $\mathrm{MgSO}_{4}$ were administered in inhaled form because this mode of administration did not require careful monitoring. In fact, in intravenous administration peripheral vasodilatation and systolic hypotension can occur and patients sometimes have unpleasant flushing, nausea, and venous phlebitis from the infusion.

The results of this study were in agreement with previous studies of Zhao et al. and Rolla and colleagues (Rolla et al., 1987; Rolla et al., 1988) that confirmed the bronchorelaxant effect of inhaled $\mathrm{NaF} 0.5 \mathrm{M}$ and inhaled $\mathrm{MgSO}_{4}$ respectively. The use of $\mathrm{NaF}$ as a therapeutic agent for asthma disease is very limited despite its bronchodilator effect demonstrated at well-defined dose both in vitro and in vivo by Zhao and Guénard (1997) and Zhao et al. (2002). This encourages us to explore the inhaled effect of $\mathrm{NaF}$ and try to determine the causes of these differences in the results. The bronchodilator effect of $\mathrm{NaF}$ is thus far poorly documented. NaF had been reported by (Stadel and Crooke, 1988; Cushing et al., 1990) to stimulate adenylate cyclase activity on smooth muscles and induced NO synthesis which would relax bronchi. The better known bronchodilator mechanism of $\mathrm{NaF}$ is induced by inhibition of the glycolytic enzyme, enolase, which converts 2-phosphoglycerate to phosphoenolpyruvate according to (Zhao and Guénard, 1997). The inhibition of glycolysis induced by $\mathrm{NaF}$ is illustrated by the sharp decrease in lactate production in its presence (Zhao et al., 2002). Inhibition of this enzyme would be expected to reduce glycolytic ATP production and impair smooth muscle contraction.

While the effect of $\mathrm{MgSO}_{4}$ administered intravenously has been confirmed by several studies (Noppen et al., 1990; Rowe et al., 2000; Gourgoulianis et al., 2001), its effect through inhalation is controversial. In fact, while some studies confirm its beneficial effect (Rolla et al., 1987; Rolla et $a l ., 1988$ ), others deny it (Hill et al., 1997). This controversy of results could be related to the serum magnesium levels of patients. Alamoudi' study (Almuodi, 2000) confirmed that hypomagnesaemia is common in chronic asthmatics. Chronic asthmatics with low $\mathrm{Mg}$ tend to have more hospitalizations than chronic asthmatic with normal Mg. Hypomagnesaemia was also associated with more severe asthma. Then, routine serum magnesium determination is recommended in patients with chronic obstructive lung disease. The lack of inhaled $\mathrm{MgSO}_{4}$ studies and its effects and the controversial results obtained leaves us both surprised and wary of such treatment. However, it does not deny in any case the bronchorelaxant effect of magnesium.

$\mathrm{MgSO}_{4}$ has been reported in many researches to inhibit the $\mathrm{Ca}^{2+}$ influx by blocking the voltage-dependent calcium channels, modulate vasoactivity by affecting the influx of extracellular 
$\mathrm{Ca}^{2+}$ through dihydropyridine-sensitive, voltage-dependent channels, which accounts for much of its relaxant action on airway (Sharma et al., 1994; Hirota et al., 1999). In vitro studies showed that magnesium ion $\left(\mathrm{Mg}^{2+}\right)$ modulates smooth muscle contractility and mediates release by antagonism of the action of calcium (Sonna et al., 1996).

Owe to this, the association of the two trace elements magnesium $(\mathrm{Mg})$ and fluoride $(\mathrm{F})$ in the form of $\mathrm{MgF}_{2}$ could represent a potential new therapeutic treatment for asthma. $\mathrm{MgF}_{2}$ was rarely used because of the low solubility of this compound which was estimated to $10^{-5}$ (Fovet and Gal, 2000). In this study, we associated $\mathrm{MgF}_{2}$ to acetic acid that increased its solubility. In fact, the dissolution of $\mathrm{MgF}_{2}$ in acetic acid led to an increase of the total molar concentrations of magnesium and fluoride in the solution compared to its dissolution in $\mathrm{NaCl} 0.9 \%: \mathrm{MgF}_{2}$ dissolved in acetic acid $\left(\mathrm{Mg}=0.08 \mathrm{mM}, \mathrm{F}=0.084 \mathrm{mM}\right.$, solubility $\left.=0.126 .10^{-3}\right) \mathrm{MgF}_{2}+\mathrm{NaCl} 0.9 \%(\mathrm{Mg}=0.04 \mathrm{mM}, \mathrm{F}=0.014$ $\mathrm{mM}$, solubility $\left.=0.521 .10^{-3}\right) . \mathrm{MgF}_{2}$ pure crystals $99.99+\%$ were used to avoid any contaminations with other elements which could fault the results like calcium that plays an important role in the contraction of smooth muscle.

$\mathrm{MgF}_{2}$ dissolved in acetic acid reversed significantly methacholine bronchial responsiveness in rats challenged by $\mathrm{MeCh}$. This result confirmed the bronchorelaxant effect of $\mathrm{MgF}_{2}$. Moreover, $\mathrm{MgF}_{2}$ had the best bronchorelaxant effect compared to $\mathrm{NaF}(0.5 \mathrm{M})$ alone or $\mathrm{MgSO}_{4}$ alone. Then, the association of magnesium and fluoride makes a powerful bronchodilator that acts at a micromolar dose range compared to $\mathrm{NaF} 0.5 \mathrm{M}$ or $\mathrm{MgSO}_{4}(15 \%)$ alone.

In the present study, inhaled doses of $\mathrm{MgSO}_{4}, \mathrm{NaF}$ and $\mathrm{MgF}_{2}$ were very low and far from the toxic doses of magnesium and fluoride (Spencer et al., 1981; Whitford, 1996; Akiniwa, 1997). It is difficult to assess the dose of $\mathrm{MgF}_{2}$ needed for the treatment of asthma as this study seems to be the first to demonstrate its bronchodilating effect in vivo. The duration of the bronchorelaxant effect of $\mathrm{MgSO}_{4}, \mathrm{NaF}$ and $\mathrm{MgF}_{2}$ is not known and needs further study.

Then, we conclude that magnesium and fluoride in salt form: $\mathrm{MgSO}_{4}, \mathrm{NaF}$ and $\mathrm{MgF}_{2}$ pure crystals act as bronchodilator. $\mathrm{MgF}_{2}$ pure acts and has a bronchodilating effect by releasing a micromolar dose range of magnesium and fluoride $(\mathrm{Mg}=0.08 \mathrm{mM}, \mathrm{F}=0.084 \mathrm{mM})$. Indeed, owing to its two different but complementary and synergic bronchorelaxant ways to induce bronchorelaxing effect. Inhaled $\mathrm{MgF}_{2}$ can reverse bronchospasma in case of asthma. In Tunisia, where this research was conducted, $\mathrm{MgF}_{2}$ is an abundant mineral and could be a useful and inexpensive tool for the treatment of asthmatics. Which, therapeutics cost is increasing constantly.

In conclusion, the present study showed that inhaled $\mathrm{MgF}_{2}$ relaxed methacholine bronchoconstriction in rats. Yet, in the light of these experiments on rats and the positive results achieved, we can move to clinical essays of $\mathrm{MgF}_{2}$ by testing its effects on bronchial hyper responsiveness.

\section{References}

Akiniwa, K. (1997). Re-examination of acute toxicity of fluoride. Fluoride. 30: 89-104.

Almuodi, O.S. (2000). Hypomagnesaemia in chronic, stable asthmatics: prevalence correlation with severity and hospitalisation. Eur. Respir. J. 16: 427-431.

Carins, C. B and Kraft, M. (2001). Magnesium attenuates the neutrophil respiratory burst in adult asthmatic patients. Acad. Emerg. Med. 14: 301-307. 
Charles, Y.C.P., Khasayar, S., Josephe, Z., Carol, P., Roy, P. and Kenneth, J. (1989). Safe and effective treatment of osteoporosis with intermittent slow release sodium fluoride: augmentation of vertebral bone and inhibition of fractures. J. Clin. Endocrinol. Metab. 68: 150-159.

Cushing, D.J., Sabouni, M.H., Brown, G.L. and Mustafa, S.J. (1990). Fluoride produces endotheliumdependent relaxation and endothelium-independent contraction in coronary artery. J. Pharmacol. Exp. Ther. 254: 28-32.

Dureuil, B. (1996). Anesthésie et hyperréactivité bronchique. EMC, Anesthésie-Reanimation 36-655-F-10, Elsevier, Paris, France.

Fovet, Y. and Gal, J.Y. (2000). Formation constants b2 of calcium and magnesium fluorides at $25^{\circ} \mathrm{C}$. Talanta. 53: 617-626.

Gourgoulianis, K.L., Catziparasidis, G., Chatziefthimiou, A. and Mlyvdas, P.A. (2001). Magnesium as a relaxing factor of airway smooth muscle. J. Aerosol. Med. 14: 301-307.

Harari, M., Barzillai, R. and Shani, J. (1998). Magnesium in the management of asthma: critical review of acute and chronic treatments, and Deutsches Medizinisches Zentrum's (DMZ's) clinical experience at the Dead Sea. J. Asthma. 35: 525-536.

Hill, J., Lewis, S. and Britton, J. (1997). Studies of the effects of inhaled magnesium on airway reactivity on histamine and adenosine monophosphate in asthmatic subjects. Clin. Exp. Allergy 27: 546-557.

Hirota, K., Sato, T., Hashimoto, Y., Yoshioka, H., Ohtomo, N., Ishihara, H. and Matsuki, A. (1999). Relaxant effect of magnesium and zinc on histamine-induced bronchoconstriction in dogs. Crit. Care Med. 27: 1159-1163.

Noppen, M., Vanmaele, L., Impens, N. and Schandevyl, W. (1990). Bronchodilating effect of intravenous magnesium sulfate in acute severe bronchial asthma. Chest 19: 373-376.

Riou, B. and Ducart, A. (1994). Kétamine editions techniques. EMC, Anesthésie-Reanimation 36-305-B-30, Elsevier, Paris, France.

Rolla, G., Bucca, C., Bugiani, M., Arossa, W. and Spinaci, S. (1987). Reduction of histamine-induced bronchoconstriction by magnesium in astmatic subjects. Allergy 42: 186-188.

Rolla, G., Bucca, C. and Caria, E. (1988). Dose- related effect of inhaled magnesium sulfate on histamine bronchial challenge in asthmatics. Drugs Exp. Clin. Res. 14: 609-612.

Rowe, B.H., Bretzlaff, J.A., Bourdon, C., Bota, J.W. and Camargo, C.A. (2000). Magnesium sulfate for treating exacerbations of acute asthma in the emergency department. Cochrane Database Syst. Rev. (database online); Issue 2.

Sharma, S.K., Bhargava, A. and Pande, J.N. (1994). Effect of parenteral magnesium sulphate on pulmonary functions in bronchial asthma. J. Asthma. 31: 109-115.

Sonna, L.A., Hirshman, C.A. and Croxto, T.L. (1996). Role of calcium channel blockade in relaxation of tracheal smooth muscle by extracellular $\mathrm{Mg}^{2+}$. Am. J. Physiol. 271: L251-L257.

Spencer, H., Osis, D. and Lender, M. (1981). Studies of fluoride metabolism in man. Sci. Total Environ. 17: $1-12$.

Stadel, J.M. and Crooke, S.T. (1988). Differential effects of fluoride on adenylate cyclase activity and guanine nucleotide regulation of agonist high-affinity receptor binding. Biochem. J. 254: 15-20.

Stephens, N.L. (2002). Airway Smooth Muscle. Lung 179: 333-373.

Sterck, P.J., Fabbri, L.M., Quanjer, P., Cockcroft, D., Anderson, D. and Malo, J.L. (2001). Tests normalisés chez l'adulte: stimulus pharmacologique, physiques et sensibilisants. Rev. Mal. Respir. 18: 67-113.

Wanger, J. (1996). Epreuves de stimulation bronchique à la méthacholine et à l'histamine. In: Exploration fonctionnelle pulmonaire, une approche pratique, Masson - Williams \& Wilkins, Paris, France.

Whitford, G.M. (1996). The metabolism and toxicity of fluoride. $2^{\text {nd }}$ revised edition, Karger, Paris, France.

Zhao, W. and Guénard, H. (1997). The inhibitory effect of fluoride on carbachol-induced bovine bronchial contraction. Respir. Physiol. 108: 171-179.

Zhao, W., Rouatbi, S., Tabka, Z. and Guénard, H. (2002). Inhaled sodium fluoride decreases airway responsiveness to acetycholine analogs in vivo. Respir. Neurobiol. 131: 245-253. 